\title{
Ovarian modulation of the oestradiol-induced LH surge in prepubertal and sexually mature gilts
}

\author{
F. Elsaesser ${ }^{1}$, N. Parvizi $^{1}$ and G. Foxcroft ${ }^{2}$ \\ ${ }^{1}$ Institute for Animal Science and Animal Behaviour (FAL), Mariensee, 31535 Neustadt/Rbge., Germany; \\ and ${ }^{2}$ Department of Animal Science, University of Albertn, Fdmonton, Canada T6G 2P5
}

\begin{abstract}
The role of ovarian secretions in modulating positive oestrogen feedback on $\mathrm{LH}$ release in late prepubertal and sexually mature gilts was studied. Gilts were either ovariectomized (OVX) at 230 days of age (sexually mature, OVX 230, control), ovariectomized at 160 days of age (pre-pubertal, OVX 160) or ovariectomized at 160 days of age and given either low, high or very high oestradiol substitution therapy (two or three Silastic implants, 5 or $8 \mathrm{~cm}$ in length) from 160 days to 230 days (OVX $160+2 \mathrm{E}_{5}$, OVX $160+2 \mathrm{E}_{8}$ and $\mathrm{OVX}$ $160+3 \mathrm{E}_{8}$, respectively). The $\mathrm{LH}$ surge responses to three i.m. injections of oestradiol benzoate given at intervals of $12 \mathrm{~h}$ (in total $10 \mu \mathrm{g}$ oestradiol benzoate $\mathrm{kg}^{-1}$ bodyweight) were compared at 260 days. An additional group of sexually mature gilts was ovariectomized at 260 days (OVX 260) and challenged with oestradiol benzoate at 360 days. LH surges with peak LH concentrations below pretreatment values (resembling LH responses to oestradiol benzoate in immature gilts) were classified as immature, and those with peak LH concentrations above pretreatment values as mature. $\mathrm{LH}$ concentrations before treatment with oestradiol benzoate were reduced $(P<0.05)$ in OVX $160+2 \mathrm{E}_{8}$ and $\mathrm{OVX} 160+3 \mathrm{E}_{8}$ gilts compared with OVX 230 (control). When compared with the control group, the time to LH surge peak was longer in OVX 260 gilts, LH peak amplitude was reduced in the OVX 160 group and the area under the curve of the $\mathrm{LH}$ surge $\left(\mathrm{ng} \mathrm{LH} \mathrm{ml}{ }^{-1}\right.$ plasma $\left.(48 \mathrm{~h})^{-1}\right)$ was less in all other groups $(P<0.05)$. Classification of LH surges by mature:immature criteria indicated a high mature:immature ratio in OVX 230 gilts (6/1) and a low ratio in OVX 160 (1/7) and OVX 260 (1/6) gilts. The long-term effect of ovariectomy was partially overcome in the OVX $160+2 \mathrm{E}_{5}$ group (mature:immature $=3 / 3$ ). However, previous exposure to supraphysiological concentrations of oestradiol (as in groups OVX $160+2 \mathrm{E}_{8}$ and OVX $160+3 \mathrm{E}_{8}$ ) resulted in a high percentage of animals $(66 \%$ and $100 \%$, respectively) that did not respond to the oestradiol benzoate challenge with an LH surge. Immediately before oestradiol benzoate administration (30 days after removal of implants) plasma oestradiol concentrations in these two groups were still high $(P<0.05)$ compared with all other groups. GnRH-induced $\left(0.2 \mu \mathrm{g} \mathrm{kg}^{-1}\right.$ bodyweight $)$ LH secretion, evaluated 10 days after treatment with oestradiol benzoate, was depressed $(P<0.05)$ in OVX $160+3 \mathrm{E}_{8}$ gilts, but not affected by age at ovariectomy. We suggest that continuous ovarian secretion is necessary for the final maturation of the LH surge mechanism in late prepubertal gilts and also for maintaining the full functionality of this mechanism in sexually mature gilts. The range over which ovarian oestrogens tune the final maturation of this process appears to be rather narrow; however, other ovarian factors may contribute to the final maturation. Furthermore, continued exposure to supraphysiological concentrations of oestradiol was found to be detrimental to the development of the LH surge mechanism.
\end{abstract}

\section{Introduction}

During the oestrous cycle of sows, plasma oestradiol concentrations increase between day 18 and day 20 because of the increased oestrogen secretion from the preovulatory follicles (Van de Wiel et al., 1981). This increase in plasma oestradiol

Revised manuscript received 5 November 1997 causes oestrus and, after an initial period of negative feedback, the release of a surge of $\mathrm{LH}$ that in turn stimulates final maturation of follicles and triggers their ovulation $36-40 \mathrm{~h}$ later. This positive oestrogen feedback on the LH surge is central to regular oestrous cycles and thus, to optimal fertility. Failure of the LH surge mechanism may result in anovulation and formation of cystic ovarian follicles (Archibong et al., 1987). 
Oestrogen acts at the hypothalamus and at the pituitary to induce an LH surge. General inhibition of the central nervous system, using pentobarbitone, blocks or delays the L.H surge in the majority of sows anaesthetized during pro-oestrus (Parvizi et al., 1976). The oestrogen-induced LH surge in ovariectomized gilts is blocked after administration of the centrally acting compound methallibure (Kesner et al., 1987), hypophysial stalk transection (Kesner et al., 1989a), or more specifically after administration of GnRH antiserum (Britt et al., 1991). In the hypothalamus, oestrogen apparently inhibits, or greatly reduces, the release of GnRH for about $48-54 \mathrm{~h}$, and then causes a punctual release of $\mathrm{GnRH}$ that induces a surge of $\mathrm{LH}$ proportional to the amount of $\mathrm{GnRH}$ released (Britt et al, 1991). In the pituitary, oestrogen acts to suppress its response to $\mathrm{GnRH}$ for a period of $12-24 \mathrm{~h}$, thereby increasing the readily releasable pool of $\mathrm{LH}$ at the time of the $\mathrm{LH}$ surge. Oestrogen does not appear to change the sensitivity of the pituitary to $\mathrm{GnRH}$ during the period of positive feedback (Kesner et al., 1987; Britt et al., 1991).

The ability of gilts to respond to oestrogen stimulation with an LH surge matures gradually as a function of age. This maturation involves a change in the amplitude and the timing of the LH response to oestradiol benzoate: in contrast to pubertal gilts, immature 60-day-old gilts display low amplitude, delayed LH surges after administration of oestradiol benzoate (Elsaesser and Foxcroft, 1978; Dial et al., 1984; Fleming and Dailey, 1985).

The control mechanisms of this maturational process are not fully understood. Opioidergic systems that inhibit the central nervous system do not seem to be of major importance in preventing mature LH surge responses to oestradiol benzoate at 60 days of age (Küneke et al., 1993). Apparently oestradiol fails to generate mature $\mathrm{LH}$ surges because the gonadotrophs of immature gilts cannot respond to enhanced $\mathrm{GnRH}$ release during the surge period in an adult-like manner (Küneke et al., 1993). While the maturation of the LH surge mechanism could not be accelerated in the immature 60-day-old gilt by pretreatment with oestradiol, the later maturation seems to be ovarian and probably oestradiol-dependent (Foxcroft et al., 1984). A significant reduction in the magnitude of LH surges, induced by oestradiol benzoate on day 160 , occurred in gilts ovariectomized on day 60 compared with gilts ovariectomized on day 130. Oestradiol substitution therapy, after ovariectomy on day 60 , effectively restored the magnitude of the $\mathrm{LH}$ response. The purpose of the present study was to evaluate the role of ovarian secretions in modulating positive oestrogen feedback on LH release in late prepubertal and sexually mature gilts.

\section{Materials and Methods}

German Landrace gilts (from the Institut für Tierzucht und Tierverhalten (FAL) Experimental Farm) in which the first oestrus is observed between 190-210 days of age, were randomly allocated, as far as possible within litters, to the following treatments:

Group 1: ovariectomy after puberty at 230 days old (OVX 230 , control, $n=7)$; group 2: ovariectomy before puberty at 160 days old (OVX 160, $n=7$ ); group 3: ovariectomy at 160 days old followed immediately by an initial s.c. oestradiol implant ( $5 \mathrm{~cm}$ in length), plus an additional implant of the same size from day 195 to day 230 when implants were removed (OVX $\left.160+2 \mathrm{E}_{5}, n=6\right)$; group 4: ovariectomy at 160 days old followed immediately by two s.c. oestradiol implants $(8 \mathrm{~cm}$ in length) and removal of the implants on day 230 (OVX $160+2 \mathrm{E}_{8}, n=6$ ); group 5: ovariectomy at 160 days old followed immediately by two s.c. oestradiol implants $(8 \mathrm{~cm}$ in length) plus an additional implant $(8 \mathrm{~cm}$ in length) from day 195 to day 230 when implants were removed (OVX $160+3 \mathrm{E}_{8}$, $n=4$ ); group 6: ovariectomy at 260 days old (OVX 260, $n=6$ ). Oestradiol implants were made from Silastic Medical Grade tubing, $4.65 \mathrm{~mm}$ diameter and $1.3 \mathrm{~mm}$ wall thickness (Dow Corning, Midland, MI.) filled with oestradiol in propylene glycol $\left(250 \mathrm{mg} \mathrm{m}^{-1}\right)$. Before insertion, implants were incubated in PBS solution for $48 \mathrm{~h}$ at $37^{\circ} \mathrm{C}$ to avoid an initial surge release after implantation in the animals. After ovariectomy, gilts were kept under natural daylight conditions and fed to appetite twice a day at the experimental farm.

The original analysis of plasma oestradiol concentrations during the implant period failed and since the plasma volume was too small to repeat the measurements reliably, twenty additional gilts ovariectomized at 160 days old were used to repeat treatments 2 to 5 (OVX 160, OVX $160+2 \mathrm{E}_{5}$, OVX $160+2 \mathrm{E}_{8}$, OVX $160+3 \mathrm{E}_{8}$ ) with five animals in each group. Groups 3 and 5 received additional implants on day 195 as described above for the main experiment. These gilts were kept individually in crates and six blood samples, for the determination of oestradiol concentrations, were taken by venepuncture from a jugular vein at intervals of approximately 10 days from day 160 to day 230.

About ten days before the challenge with oestradiol benzoate (Progynon B Oleosum, $5 \mathrm{mg} \mathrm{ml}^{-1}$, Schering AG, Berlin) gilts were kept individually in animal crates in a purpose-built environmentally controlled building adopting the natural seasonal photoperiod ( $17 \mathrm{~h}$ light:7 $\mathrm{h}$ dark) and temperature (20$22^{\circ} \mathrm{C}$ ). Gilts were fed to appetite at 6:30 h and 13:00 h. All gilts were fitted surgically with an indwelling jugular catheter, as described by Ellendorff et al. (1977), 3-4 days before the first blood sample was taken. Oestradiol benzoate $\left(10 \mu \mathrm{g} \mathrm{kg}^{-1}\right.$ bodyweight, i.m.) was given to all gilts in groups $1-5$ at 260 days old and to gilts of group 6 (OVX 260) at 360 days. In order to produce plasma oestradiol profiles that resembled more closely the endogenous presurge increase in oestradiol, the total dose of oestradiol benzoate was spread over three injections as follows: $5 \mu \mathrm{g} \mathrm{kg}^{-1}$ bodyweight at 11:00 h on day 0 of the experiment; $2.5 \mu \mathrm{g} \mathrm{kg}^{-1}$ bodyweight at 23:00 $\mathrm{h}$ on day 0 and $2.5 \mu \mathrm{g} \mathrm{kg}^{-1}$ bodyweight at 11:00 h on day 1. Ten days after the challenge with oestradiol benzoate, all gilts received a single i.v. injection of $0.2 \mu \mathrm{g} \mathrm{GnRH} \mathrm{(Sigma,} \mathrm{W-8024}$ Deisenhofen) $\mathrm{kg}^{-1}$ bodyweight at a concentration of $10 \mu \mathrm{g}$ GnRH ml ${ }^{-1}$ physiological saline.

\section{Blood sampling}

Blood samples $(2 \mathrm{ml}$ ) were taken every $4 \mathrm{~h}$ for analysis of LH starting at $-24 \mathrm{~h}$ before and continuing until $120 \mathrm{~h}$ after the first injection of oestradiol benzoate (time 0 ). Additional blood samples $(6 \mathrm{ml})$ were taken over the same period at intervals of $12 \mathrm{~h}$ for the determination of oestradiol. When it was dark, red 
light forehead torches were used during sampling. Blood samples before and after the $\mathrm{GnRH}$ injection were collected at $-30,-15,0,5,10,15,20,30,40,60,90,120$ and $180 \mathrm{~min}$. Heparin was added immediately to the samples which were then centrifuged for $20-30 \mathrm{~min}$ at $1000 \mathrm{~g}$ and plasma was stored at $-20^{\circ} \mathrm{C}$ until analysis.

\section{Hormone analysis}

Plasma LH was determined in duplicate $100 \mu$ l samples by an homologous radioimmunoassay (Pomerantz et al., 1974; Ponzilius et al., 1986). A specific antiserum (UCB Porcine-AntiLH, UCB; Brussels) that had been raised in rabbits against porcine $\mathrm{LH}$ was diluted to $1: 80000$. Highly purified porcine $\mathrm{LH}$ (LER-786-3) had a biological activity of 0.65 NIH-LH-SIU $\mathrm{mg}^{-1}$ and was used for both the standard stock solution and for ${ }^{125}$ I-labelled hormone tracer. The sensitivity of the LH assay was $0.2 \mathrm{ng} \mathrm{ml}^{-1}$ plasma at $90 \% \mathrm{~B}: \mathrm{B}_{0}$. The intra- and interassay coefficients of variation were 3.5 and 6.0 , respectively. Gilts from different treatments were represented in each assay.

Plasma concentrations of oestradiol after treatment with oestradiol benzoate were analysed by a specific radioimmunoassay (Elsaesser et al., 1978; Elsaesser and Parvizi, 1980). Oestradiol antiserum (E12) was obtained by immunizing rabbits against oestradiol-6-carboxy-o-methyl-oxime-BSA and diluted 1:100 000. Crossreactions were: oestradiol benzoate $1.5 \%$; oestrone $0.6 \%$, oestriol $0.1 \%$ and $<0.1 \%$ with progesterone, testosterone and hydrocortisone. Intra- and interassay coefficients of variation were 9.0 and $13.3 \%$, respectively. Plasma volume for analysis was $500-1000 \mu \mathrm{l}$ in duplicate. The sensitivity of the assay at $90 \% \mathrm{~B}: \mathrm{B}_{0}$ was $8 \mathrm{pg} \mathrm{ml}^{-1}$ plasma when $1000 \mu$ l plasma were used.

Plasma oestradiol concentrations before oestradiol benzoate treatment and during the implantation period (repetition experiment) were measured using a different, very sensitive method, validated for pig plasma (Cox et al., 1987). The antibody (E2-6\#3) was kindly provided by N. R. Mason (Eli Lilly Corp., Indianapolis, IN) and ${ }^{125} \mathrm{I}$-labelled oestradiol (Amersham, Braunschweig) was used as a tracer. Intra- and interassay coefficients of variation were $11.3 \%$ and $19.7 \%$, respectively. Plasma volume for analysis was $1000 \mu \mathrm{l}$ in duplicate and the sensitivity of the assay at $90 \% \mathrm{~B}: \mathrm{B}_{0}$ was $1.5 \mathrm{pg} \mathrm{ml}^{-1}$.

During all periods of oestradiol-substitution treatment, a subjective assessment was made of the degree of vulval enlargement and reddening. At slaughter (14 days after oestradiol benzoate treatment) uterine wet masses were recorded and taken as an additional index of previous oestrogenic stimulation.

\section{Statistical analyses}

The whole experiment was divided, on the basis of previous findings (Elsaesser and Foxcroft, 1978), into four periods for the evaluation of the results: (1) a pretreatment period from -24 to $\mathrm{O} h$ before oestradiol benzoate injection; (2) a negative feedback period from 4 to $48 \mathrm{~h}$; (3) a positive feedback period from 52 to $96 \mathrm{~h}$ and (4) a post-surge period from 100 to $120 \mathrm{~h}$. Two-way ANOVA within the surge period, using the GLM procedure for repeated measurements, revealed abnormal distribution and unequal variances even after logarithmic transformation of $\mathrm{LH}$ concentrations. Therefore, the area under the curve of the $\mathrm{LH}$ surge (ng LH ml ${ }^{-1}$ plasma $(48 \mathrm{~h})^{-1}$ ) was calculated for each animal by subtracting the mean LH concentration during the negative feedback period from the $\mathrm{LH}$ concentration during positive feedback (samples taken $52 \mathrm{~h}$ to $96 \mathrm{~h}$ after oestradiol benzoate treatment) and summing these values. Treatment effects on the characteristics of the induced LH surges were evaluated additionally using the following criteria: $\mathrm{A}=$ time to the onset of $\mathrm{LH}$ surge $(\mathrm{h})$, calculated as the first time after the period of oestradiol benzoate-induced $\mathrm{LH}$ suppression that $\mathrm{LH}$ concentration increased above $1 \mathrm{ng} \mathrm{ml}^{-1}$ plasma. $B=$ time to $\mathrm{LH}$ surge peak $(\mathrm{h})$, defined as the time to the highest $\mathrm{LH}$ concentrations occurring in the first $20 \mathrm{~h}$ of stimulated LH secretion after the time of onset defined as A. (This should ensure that high LH concentrations resulting from release from oestrogen-evoked suppression are not being used). $\mathrm{C}=$ peak $\mathrm{LH}$ amplitude $\left(\mathrm{ng} \mathrm{ml}^{-1}\right)$ corresponding to $\mathrm{LH}$ concentration at time B. Each LH 'surge' was also classified as immature or mature. Classification of $\mathrm{LH}$ surges as immature is based on previous findings (Foxcroft et al., 1984) that immature 60-day-old gilts respond to oestradiol benzoate with LH surges of low magnitude and that in 160-day-old gilts, that had been ovariectomized at 60 days, the maximum LH concentration during the surge period did not exceed the maximum $\mathrm{LH}$ concentrations in the period before oestradiol benzoate treatment. For a surge to be classified as mature, the maximum LH concentration during the surge period had to exceed any of the $\mathrm{LH}$ concentrations in the period before oestradiol benzoate treatment, again indicating that the increase in LH concentrations did not represent simply the removal of oestradiol negative feedback.

The LH response to GnRH was characterized by determining maximum LH concentrations (peak LH) and the area under the curve values (ng LH ml ${ }^{-1}$ plasma $(120 \mathrm{~min})^{-1}$ ) by subtracting the mean pretreatment $\mathrm{LH}$ concentrations from the $\mathrm{LH}$ concentrations +5 to $+120 \mathrm{~min}$ after $\mathrm{GnRH}$ and summing these values.

Data were subjected to least-squares analyses of variance (one-way) using SigmaStat ${ }^{(M)}$ Statistical Software (Jandel Scientific, 1992). When treatment effects were significant, the Student-Newman-Keuls method was used for pairwise multiple comparisons.

\section{Results}

\section{Concentration of oestradiol in plasma}

Plasma oestradiol concentrations during the period of oestradiol substitution therapy were $\leq 1.5 \mathrm{pg} \mathrm{ml}^{-1}$ in OVX 160 gilts. In OVX $160+2 \mathrm{E}_{5}$, OVX $160+2 \mathrm{E}_{8}$ and $\mathrm{OVX}$ $160+3 \mathrm{E}_{8}$ gilts, mean plasma oestradiol concentrations ( \pm SEM) from day 160 to day 195 were $6.2 \pm 1.8,13.5 \pm 0.9$ and $10.2 \pm 2.1 \mathrm{pg} \mathrm{ml}^{-1}$, respectively, and from day 195 to day $230,7.7 \pm 0.7,12.2 \pm 1.1$ and $18.4 \pm 3.8 \mathrm{pg}$ oestradiol $\mathrm{ml}^{-1}$ plasma, respectively. Treatment comparisons between groups indicated: OVX $160+2 \mathrm{E}_{5}<\mathrm{OVX} 160+2 \mathrm{E}_{8}$, OVX $160+3 \mathrm{E}_{8} ;$ $P<0.005$. Pretreatment concentrations of oestradiol in plasma 


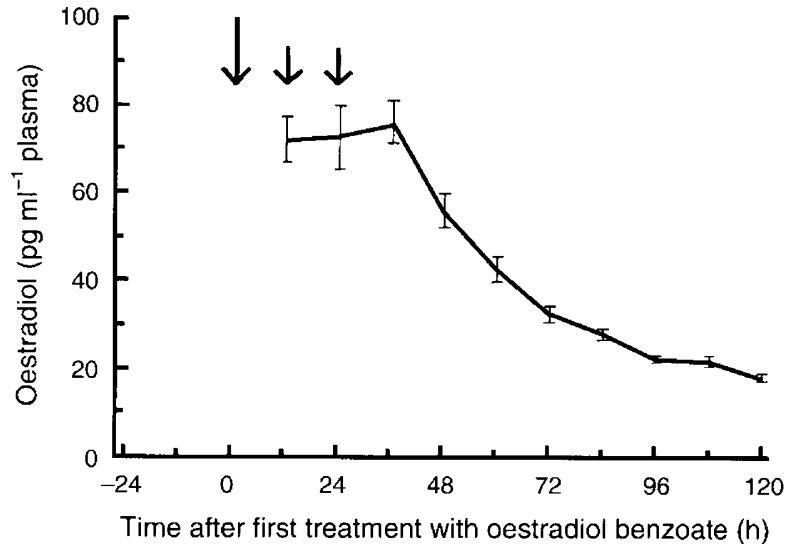

Fig. 1. Mean ( \pm SEM) plasma oestradiol concentrations in gilts $(n=36)$ after i.m. administration of a total dose of $10 \mu \mathrm{g} \mathrm{kg}^{-1}$ bodyweight oestradiol benzoate given as three injections of $5,2.5$ and $2.5 \mu \mathrm{g} \mathrm{kg}$ bodyweight, respectively (arrows). For pretreatment values see text.

immediately before oestradiol benzoate treatment were $4.2 \pm 1.1 \mathrm{pg} \mathrm{ml}^{-1}$ and $11.5 \pm 2.8 \mathrm{pg} \mathrm{ml}^{-1}$ in OVX $160+2 \mathrm{E}_{8}$ and OVX $160+3 \mathrm{E}_{8}$, respectively, and $\leq 1.5 \mathrm{pg} \mathrm{ml}^{-1}$ in all other groups. Twelve hours after the first treatment with oestradiol benzoate, oestradiol concentrations had increased to $72 \pm 5 \mathrm{pg}$ oestradiol $\mathrm{ml}^{-1}$ (Fig. 1) and then remained fairly constant for the next $24 \mathrm{~h}$; thereafter, concentrations decreased, but remained above pretreatment values for the remainder of the sampling period. There were no group differences in the pattern of plasma oestradiol concentrations after oestradiol benzoate treatment.

\section{Vulval changes and uterine masses}

Vulva size before oestradiol benzoate treatment was markedly reduced in OVX 160 and OVX 260 gilts compared with age-matched intact gilts in the experimental farm. Substitution treatment with two oestradiol implants $5 \mathrm{~cm}$ in length compensated for ovariectomy. Substitution with two or three implants $8 \mathrm{~cm}$ in length induced vulva hypertrophy (compared with intact gilts of the experimental farm). In these gilts at least one oestrus, checked using a boar, was observed soon after insertion of oestradiol implants. The mean uterine masses ( \pm SEM) of groups $1,2,3,4,5$ and 6 were $116 \pm 11,79 \pm 5$, $105 \pm 7,199 \pm 16,224 \pm 67$ and $327 \pm 35 \mathrm{~g}$, respectively, and were significantly affected by treatment $(P<0.05)$. Treatment comparisons between groups indicated: $(1,2,3)<(4,5)<(6)$; $P<0.05$.

\section{Concentration of LH in plasma}

LH concentrations before the challenge with oestradiol benzoate were not affected by the age at which OVX was performed. However, pretreatment LH concentrations were reduced $(P<0.05)$ in animals that had received two or three Silastic oestradiol implants $8 \mathrm{~cm}$ in length, although the implants had been removed 30 days before the challenge with oestradiol benzoate (Fig. 2a). Previous oestradiol-substitution therapy with three implants also resulted in decreased LH concentrations in the period of negative feedback compared with OVX $160+2 \mathrm{E}_{5}$. Concentrations after the surge were also affected by pretreatment. OVX 160 and OVX 260 gilts had higher mean post-surge LH concentrations than OVX $160+3 \mathrm{E}_{8}$ gilts $(P<0.05)$ (probably because of the delay in the timing of the LH surge response to oestradiol benzoate in these long-term ovariectomized animals).

Pretreatment affected LH surge characteristics. The largest area under the curve (ng LH ml ${ }^{-1}\left(48 \mathrm{~h}^{-1}\right.$ ) was measured in OVX 230 control gilts that had been ovariectomized only 30 days before the challenge with oestradiol benzoate; OVX $160+3 \mathrm{E}_{8}$ gilts displayed the smallest area under the curve (Fig. $2 \mathrm{a}$ and Table 1). Classification of $\mathrm{LH}$ surges as mature or immature (Table 1) indicated a high mature:immature ratio in OVX 230 gilts (6/1) and a low ratio in OVX $160(1 / 7)$ and OVX 260 (1/6) gilts. The effect of long-term ovariectomy could be overcome partially by low oestradiol substitution therapy $\left(\mathrm{OVX} 160+2 \mathrm{E}_{5}\right)$, whereas previous exposure to high, presumably supraphysiological concentrations of oestradiol (as indicated by uterine masses, OVX $160+2 \mathrm{E}_{8}$ or OVX $160+3 \mathrm{E}_{8}$ ) resulted in a high percentage of animals that did not respond to oestradiol benzoate treatment with an $\mathrm{LH}$ surge. Time to onset of an LH surge was not affected significantly by pretreatment, but time to LH surge peak was longer $(P<0.05)$ in OVX 260 gilts compared with controls. LH peak amplitude was depressed in OVX 160 gilts $(P<0.05)$ compared with controls.

LH secretion after stimulation by GnRH was not affected by age at ovariectomy but was affected by the amount of oestradiol substitution (Fig. 2b). Maximum LH concentrations were achieved 15 to $20 \mathrm{~min}$ after $\mathrm{GnRH}$ treatment and these concentrations were lower in OVX $160+2 \mathrm{E}_{8}$ and $\mathrm{OVX}$ $160+3 \mathrm{E}_{8}$ compared with all other groups $(P<0.05)$. In addition, $\mathrm{GnRH}$-induced $\mathrm{LH}$ secretion (ng LH ml ${ }^{-1}$ plasma $(120 \mathrm{~min})^{-1}$ ) was depressed in OVX $160+3 \mathrm{E}_{8}$ gilts compared with controls.

\section{Discussion}

In the present study, classification of $\mathrm{LH}$ surges as mature or immature indicated a high mature:immature ratio in OVX 230 gilts (control) and a low ratio in OVX 160 and OVX 260 gilts. The low amplitude of the LH response to oestradiol benzoate in long-term ovariectomized animals resembles those induced by oestradiol benzoate treatment in gilts at 60 days old (Elsaesser and Foxcroft, 1978; Foxcroft et al., 1984). Thus, in the absence of continuous ovarian secretions, the LH surge mechanism of gilts returns to the immature state. In the present study, the interval from oestradiol benzoate treatment to the onset and to the peak of the LH surge was consistently increased in long-term ovariectomized gilts; this was a result of the increased proportion of immature responses in these treatment groups, which were characteristic of 60-day-old gilts from previous studies (Elsaesser and Foxcroft, 1978; Foxcroft et al., 1984). We, therefore, conclude that, in addition to the prepubertal maturation (Foxcroft et al., 1984), the final maturation of the LH surge mechanism, and the maintenance of this mechanism in sexually mature gilts is dependent on the ovary. 

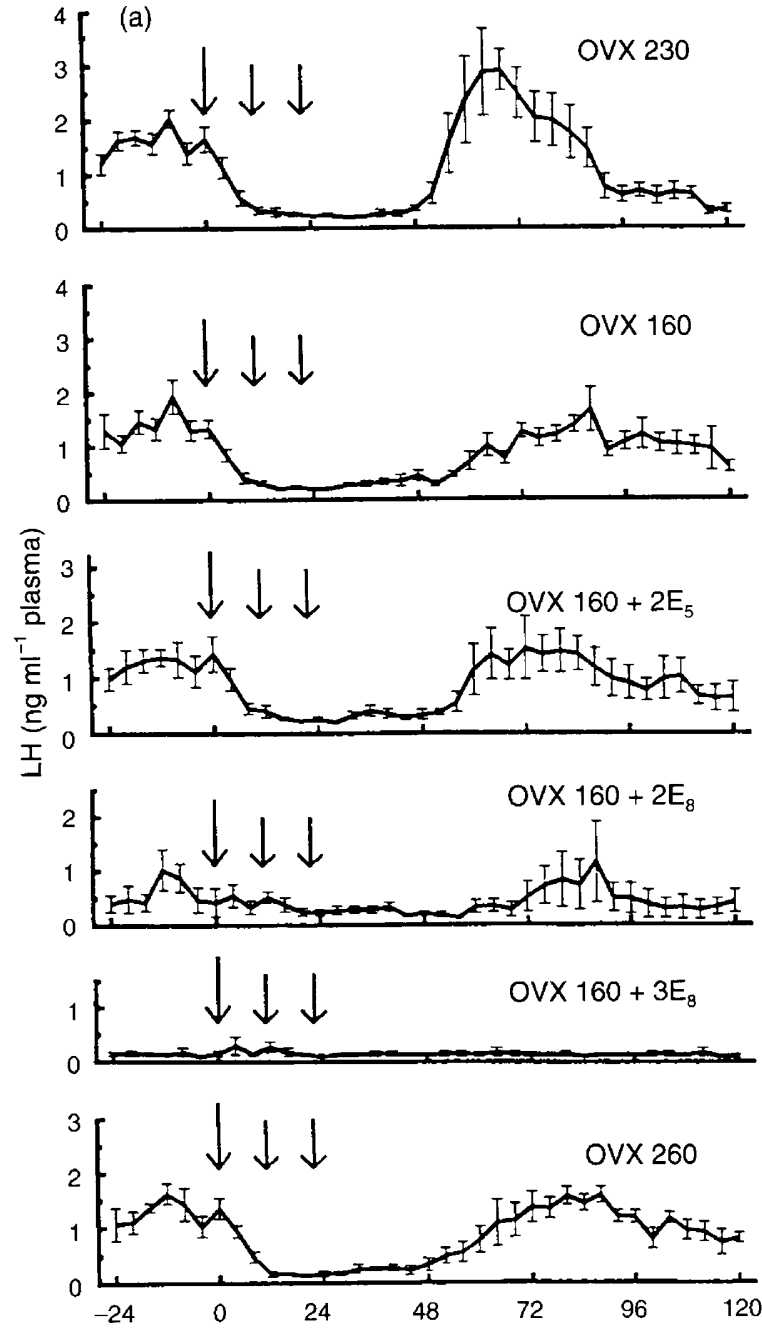

Time after first treatment with oestradiol benzoate $(\mathrm{h})$
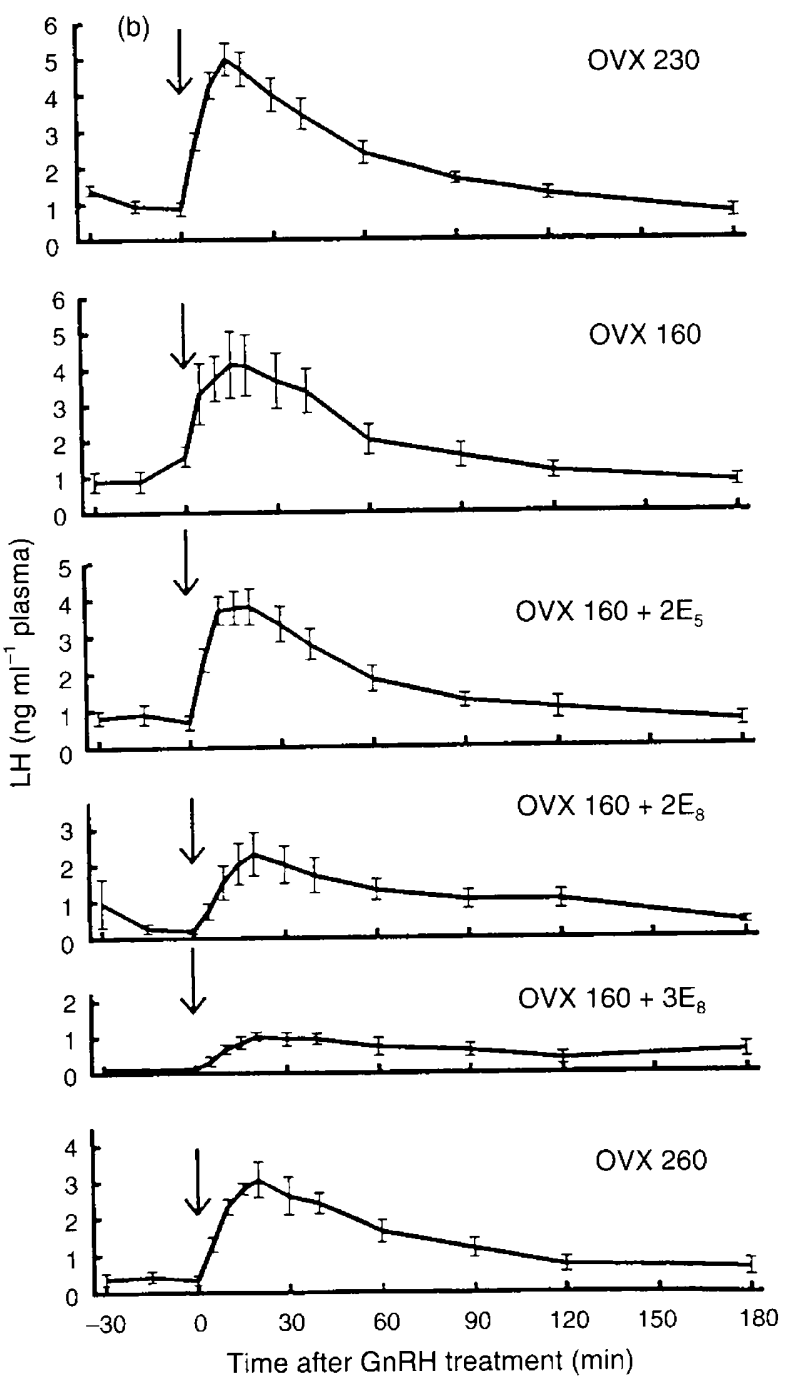

Fig. 2. Mean ( \pm SEM) plasma concentrations of $\mathrm{LH}$ in gilts (a) before and after i.m. administration of $10 \mu \mathrm{g}$ oestradiol benzoate $\mathrm{kg}^{-1}$ bodyweight $^{-1}$ (arrows) and (b) before and after i.v. administration of $0.2 \mu \mathrm{g} \mathrm{GnRH} \mathrm{kg}{ }^{-1}$ bodyweight (arrows) 10 days later. Gilts were either ovariectomized at 230 days of age (OVX 230, control, $n=7$ ), ovariectomized at 160 days old (OVX 160, $n=7$ ), or ovariectomized at 160 days and given low (OVX $\left.160+2 \mathrm{E}_{5}, n=6\right)$, high (OVX $\left.160+2 \mathrm{E}_{8}, n=6\right)$, or very high (OVX $\left.160+3 \mathrm{E}_{8}, n=4\right)$ oestradiol substitution therapy from 160 days to 230 days. The LH surge responses to oestradiol benzoate were compared at 260 days. OVX 260 gilts were ovariectomized at 260 days old and challenged with oestradiol benzoate at 360 days.

Another maturational event, the ability of prepubertal gilts to respond to increased oestradiol concentrations with multiple circadian surges of $\mathrm{LH}$, is lost as gilts become mature, but before they become cyclic (Dial et al., 1984). In the study by Foxcroft et al. (1984), the LH surges in response to oestradiol benzoate treatment at 160 days were typically biphasic, with LH surges occurring on the third or fourth night after oestradiol benzoate, regardless of whether the gilts had been ovariectomized at 60 or 130 days of age, or whether they had received oestradiol substitution treatment. In all treatment groups in the present study, only one surge of LH followed treatment with oestradiol benzoate, as apparent from the mean changes in plasma LH concentrations but also as evidenced from the $\mathrm{LH}$ changes in individual gilts. These findings suggest that the maturational change from multiphasic to single LH surge responses to oestradiol occurs between 160 and 260 days of age and is not dependent on the presence of the ovary.
Also, once this ability to respond to oestradiol benzoate with single LH surges has been established, it is not affected by the withdrawal of ovarian secretions, as indicated by the behaviour of the OVX 260 group. Alternatively, since in the study by Foxcroft et al. (1984), oestradiol benzoate was administered as a single injection, whereas, in the present study, it was delivered by three injections of lower doses, it is possible that the multiphasic LH responses are more associated with the pattern of oestradiol delivery rather than the age of the gilt.

In the study by Foxcroft $e t$ al. (1984), oestradiol substitution therapy (two implants $5 \mathrm{~cm}$ long), after ovariectomy, effectively restored the magnitude of the LH response to oestradiol benzoate at 160 days. In the context of the final maturation of the LH surge mechanism, the role of ovarian oestrogen is more difficult to interpret. Only half of the animals in the OVX $160+2 \mathrm{E}_{5}$ group displayed a mature, distinct single $\mathrm{LH}$ surge 
Table 1. Mean ( \pm SEM) LH surge characteristics ( 52 to $96 \mathrm{~h}$ after treatment with oestradiol benzoate) in female pigs classified by treatment and mature (M)/immature (IM) criteria

\begin{tabular}{|c|c|c|c|c|c|c|c|}
\hline \multirow[b]{2}{*}{ Group } & \multirow[b]{2}{*}{ Treatment } & \multirow[b]{2}{*}{$\begin{array}{l}\text { Sub-group } \\
\text { M/IM }\end{array}$} & \multirow[b]{2}{*}{$n$} & \multirow{2}{*}{$\begin{array}{l}\text { Area under the } \\
\text { curve of the } \\
\text { LH surge } \\
\text { (ng } \mathrm{LH} \mathrm{ml} \mathrm{ml}^{-1} \\
\text { plasma } 48 \mathrm{~h}^{-1} \text { ) }\end{array}$} & \multicolumn{3}{|c|}{ LH surge characteristics } \\
\hline & & & & & $\begin{array}{c}\text { Time to } \\
\text { onset } \\
\text { (h) }\end{array}$ & $\begin{array}{c}\text { Time to } \\
\text { peak } \\
\text { (h) }\end{array}$ & $\begin{array}{l}\text { Peak LH } \\
\text { amplitude } \\
\left(\mathrm{ng} \mathrm{ml}^{-1}\right)\end{array}$ \\
\hline 1 & OVX after puberty at 230 days old (control) & All & 7 & $72.4 \pm 11.2^{\mathrm{a}}$ & $59 \pm 2$ & $66 \pm 1^{a}$ & $3.9 \pm 0.5^{\mathrm{a}}$ \\
\hline \multirow[t]{3}{*}{2} & OVX before puberty at 160 days old & All & 7 & $33.2 \pm 4.0^{\mathrm{b}}$ & $71 \pm 3$ & $77 \pm 3$ & $1.6 \pm 0.1^{b}$ \\
\hline & & $\mathrm{M}$ & I & 39.2 & 60 & 64 & 1.9 \\
\hline & & IM & 6 & $32.0 \pm 4.4$ & $73 \pm 3$ & $79 \pm 3$ & $1.6 \pm 0.1$ \\
\hline \multirow[t]{3}{*}{3} & OVX at 160 days old $+2 \mathrm{E}_{5}$ & All & 6 & $39.6 \pm 7.6^{\mathrm{b}}$ & $69 \pm 4$ & $73 \pm 4$ & $2.5 \pm 0.5$ \\
\hline & & $\mathrm{M}$ & 3 & $48.8 \pm 4.4$ & $60 \pm 2$ & $64 \pm 0$ & $3.2 \pm 0.7$ \\
\hline & & IM & 3 & $30.4 \pm 13.6$ & $77 \pm 1$ & $83 \pm 1$ & $1.7 \pm 0.6$ \\
\hline 5 & OVX at 160 days $+3 \mathrm{E}_{8}$ & - & 4 & $0.4 \pm 0.4^{c}$ & & no surge & \\
\hline \multirow[t]{3}{*}{6} & OVX at 260 days old (oestradiol benzoate given at 360 days) & All & 6 & $42.8 \pm 6.8^{b}$ & $69 \pm 3$ & $83 \pm 4^{b}$ & $2.0 \pm 0.2$ \\
\hline & & M & 1 & 74.4 & 56 & 64 & 3.1 \\
\hline & & IM & 5 & $36.8 \pm 3.6$ & $72 \pm 3$ & $86 \pm 2$ & $1.8 \pm 0.1$ \\
\hline
\end{tabular}

OVX: ovariectomized.

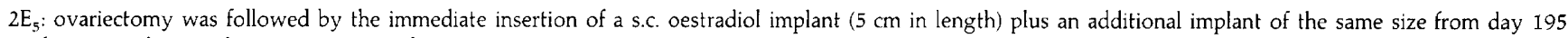
to day 230 , when implants were removed.

$2 \mathrm{E}_{8}$ : ovariectomy was followed by the immediate insertion of two s.c. oestradiol implants ( $8 \mathrm{~cm}$ in length) and removal of the implants at day 230 .

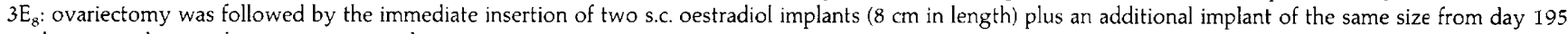
to day 230 , when implants were removed.

Treatment means (sub-group 'All') within a column with different superscripts are significantly different $(P<0.05)$.

response to oestradiol benzoate, although mean uterine masses in this group (similar to those in the OVX 230 group) suggest that plasma oestradiol concentrations present in intact animals of this age had been mimicked. Oestradiol concentrations in OVX $160+2 \mathrm{E}_{5}$ gilts during substitution therapy were slightly higher than those reported for prepubertal, intact gilts of this age by Elsaesser et al. (1991) and those reported for cyclic gilts during dioestrus by Cox et al. (1994) using the same oestradiol radioimmunoassay as in the present study. However, a higher plane of oestradiol substitution (as suggested by the uterine masses and oestradiol concentrations during substitution therapy) in the OVX $160+2 \mathrm{E}_{8}$ group resulted in a high proportion of gilts (4/6) not responding to oestradiol benzoate treatment with an LH surge. These findings suggest that the range in which ovarian oestrogens may tune the final maturation of this process is very narrow and that other ovarian factors may contribute to the final maturation.

It has been shown by Kesner et al. (1989b) that an initial decrease in plasma LH concentrations (negative feedback) after oestradiol benzoate treatment, which apparently increases the readily releasable pool of $\mathrm{LH}$, is a prerequisite for the full expression of the oestrogen-induced LH surge. In the study reported here, no relationship existed between the degree of negative feedback inhibition and the occurrence of mature $\mathrm{LH}$ surge responses. Britt et al. (1991) demonstrated that the magnitude of the LH surge was positively related to the dose and frequency of GnRH-analogue pulses applied during 54-96 h after oestradiol benzoate treatment in gilts, in which endogenous GnRH had been specifically blocked by the administration of GnRH antiserum. Thus, it may be that in long-term ovariectomized gilts, the capacity to produce a GnRH surge in response to oestradiol has decreased due to deprivation of ovarian secretions, possibly oestradiol. Although there is no evidence in pigs to support this suggestion, it has become clear from work in rats that oestrogen accelerates the maturation of synaptic morphology and increases the number of axodentritic synapses in the arcuate nucleus, a key hypothalamic nucleus in the control of LH secretion (Arai and Matsumoto, 1978). In addition, antisera against oestrogen attenuate development of neurites by hypothalamic explants from newborn rats (Toran-Allerand, 1976).

Although the $\mathrm{LH}$ response to a single, low dose i.v. injection of $\mathrm{GnRH}$ is probably not an indicator of the readily releasable pools of LH necessary for the generation of an LH surge (Kesner et al., 1989b), the LH responses to GnRH suggest that the regression of the $\mathrm{LH}$ surge mechanism in the long-term ovariectomized animals is not associated with an obvious impairment of gonadotroph function, again pointing to a hypothalamic site of action of ovarian secretions. However, at least one cause of the impaired positive feedback response to 
oestradiol in gilts receiving supraphysiological concentrations of substituted oestradiol is a decreased responsiveness of the gonadotrophs to $\mathrm{GnRH}$, possibly as a consequence of direct negative feedback effects of surprisingly still elevated oestradiol on pituitary synthesis of $\mathrm{LH}$ or due to pathological effects of oestradiol on the hypothalamus. High doses of oestradiol have been shown to exert a neurotoxic effect on $\beta$-endorphin neurones in the arcuate nucleus of rats. This effect ultimately results in chronically attenuated plasma $\mathrm{LH}$ patterns and a severely attenuated LH response to GnRH (for review see Brawer et al., 1993). The strong inhibition of pretreatment plasma $\mathrm{LH}$ concentrations in the OVX $160+2 \mathrm{E}_{8}$ gilts and in particular in the OVX $160+3 \mathrm{E}_{8}$ gilts suggest a similar mechanism of action of supraphysiological concentrations of oestradiol in pigs, or alternatively, this strong inhibition of plasma LH concentrations is due to the still increased plasma concentrations of oestradiol 30 days after removal of the implants.

The impaired positive feedback response to oestradiol in gilts with a higher plane of oestradiol substitution is reminiscent of the lack of LH surge response to oestradiol benzoate treatment during early lactation (Elsaesser and Parvizi, 1980). Findings in early weaned sows indicate that the dysfunction of the oestrogen positive-feedback mechanism during early lactation is not merely due to the suckling stimulus, but may be related to increased oestrogen concentrations during early and mid-lactation (see Varley and Foxcroft (1990)), or to the prolonged exposure of pregnant sows to high concentrations of oestrogens. Edwards and Foxcroft (1983a) and Kirkwood et al. (1984a) observed a reduced preovulatory LH surge at the first oestrus when sows were weaned after 3 weeks and 10 days of lactation, respectively. Apparently the hypothalamicpituitary unit is relatively insensitive to oestradiol shortly after parturition, since compared with later stages of lactation, impaired LH surge responses to oestradiol benzoate were observed after weaning at 3 weeks (Edwards and Foxcroft, 1983b) or 10 days of lactation (Kirkwood et al., 1984b). The more recent data of Sesti and Britt (1993) indicate that a smaller number of surges of $\mathrm{LH}$, induced by oestradiol benzoate treatment, occur at mid- rather than during late lactation, apparently because of inadequate releasable pools of pituitary LH. However, whether the dysfunction of the oestrogen positive-feedback mechanism in early lactation is indeed a consequence of the increased plasma oestrogen concentrations (see Varley and Foxcroft, 1.990) or due to the prolonged exposure of pregnant sows to high concentrations of oestrogen needs further investigation, in particular since during pregnancy sows are also exposed to high concentrations of progesterone.

In conclusion, continuous ovarian secretions, possibly oestradiol in a rather narrow physiological range, appear to be necessary, not only for the final maturation of the LH surge mechanism, but also to maintain the full functionality of this mechanism in sexually mature gilts. Continued exposure to high, presumably supraphysiological concentrations of oestradiol is detrimental to the development of the LH surge mechanism.

The authors gratefully acknowledge the excellent technical assistance of U. Buntrock, R. Ronge and the late A. Schulte-Derne.

\section{References}

Arai $Y$ and Matsumoto A (1978) Synapse formation of the hypothalamic arcuate nucleus during post-natal development in the female rat and its modification by neonatal oestrogen treatment Psychoneuroendocrinology 3 $31-45$

Archibong AE, England DC and Stormshak F (1987) Ovulation and embryonic survival in pubertal gilts treated with gonadotropin releasing hormone Journal of Animal Science 65 752-755

Brawer JR, Beaudet A, Desjardins GC and Schipper HM (1993) Mini review: Pathologic effect of oestradiol on the hypothalamus Biology of Reproduction $49647-652$

Britt JH, Esbenshade KL and Ziecik AJ (1991) Roles of oestradiol and gonadotropin-releasing hormone in controlling negative and positive feedback associated with luteinizing hormone surge in ovariectomized pigs Biology of Reproduction 45 478-485

Cox NM, Ramirez JL, Matamoros LA, Bennett WA and Britt JH (1987) Influence of season on estrous and luteinizing hormone responses to estradiol benzoate in ovariectomized sows Theriogenology 27 315-405

Cox NM, Meurer KA, Carlton CA, Tubbs RC and Mannis DP (1994) Effect of diabetes mellitus during the luteal phase of the oestrous cycle on preovulatory follicular function, ovulation and gonadotrophins in gilts Journal of Reproduction and Fertility 101 77-86

Dial GD, Dial OK, Wilkinson RS and Dziuk PJ (1984) Endocrine and ovulatory responses of the gilt to exogenous gonadotropins and oestradiol during sexual maturation Biology of Reproduction 30 289-299

Edwards S and Foxcroft GR (1983a) Endocrine changes in sows weaned at two stages of lactation Journal of Reproduction and Fertility 67 161-172

Edwards S and Foxcroft GR (1983b) Response of sows to oestradiol benzoate treatment after weaning at two stages of lactation Journal of Reproduction and Fertility 67 173-180

Ellendorff F, Parvizi N, Elsaesser F and Smidt D (1977) The miniature pig as an animal model in endocrine and neuroendocrine studies of reproduction Laboratory Animal Science 27 822-830

Elsaesser F and Foxcroft GR (1978) Maturational changes in the characteristics of oestrogen-induced surges of luteinizing hormone in immature domestic gilts Journal of Endocrinology 78 455-456

Elsaesser $\mathbf{F}$ and Parvizi N (1980) Partial recovery of the stimulatory oestrogen feedback action on LH release during late lactation in the pig Journal of Reproduction and Fertility 59 63-67

Elsaesser F, Parvizi N and Ellendorff F (1978) Steroid feedback on luteinizing hormone secretion during sexual maturation in the pig Journal of Endocrinology 78 329-342

Elsaesser F, Parvizi N and Schmitz U (1991) Inhibitory feedback action of oestradiol on tonic secretion of luteinizing hormone in pre- and postpubertal gilts Animal Reproduction Science 25 155-168

Fleming MW and Dailey RA (1985) Longitudinal study of the surge of gonadotropins induced by exogenous hormones in prepubertal gilts Endocrinology 116 1893-1898

Foxcroft GR, Elsaesser F, Stickney K, Haynes NB and Back HL (1984) Ovarian oestrogen-dependent maturation of the LH/FSH surge mechanism during prepubertal development in the gilt Journal of Endocrinology $101371-$ 380

Kesner JS, Kraeling RR, Rampacek GB and Johnson B (1987) Absence of an oestradiol-induced surge of luteinizing hormone in pigs receiving unvarying pulsatile gonadotropin-releasing hormone stimulation Endocrinology 121 1862-1869

Kesner JS, Estienne MJ, Kraeling RR and Rampacek GB (1989a) Luteinizing hormone and prolactin secretion in hypophysial-stalk-transected pigs given oestradiol and pulsatile gonadotropin-releasing hormone Neuroendocrinology $49502-508$

Kesner JS, Price-Taras EA, Kraeling RR, Rampacek GB and Barb CR (1989b) Negative feedback as an obligatory antecedent to the oestradiol-induced luteinizing hormone surge in ovariectomized pigs Biology of Reproduction 41 409-413

Kirkwood RN, Lapwood KR, Smith WC and Anderson IL (1984a) Plasma concentrations of $\mathrm{LH}$, prolactin, oestradiol-17 $\beta$ and progesterone in sows weaned after lactation for 10 or 35 days Journal of Reproduction and Fertility 70 95-102

Kirkwood RN, Lapwood KR, Smith WC, Moller K and Garrick DJ (1984b) Effects of oestradiol benzoate treatment on the reproductive performance and 
endocrine status of sows after lactations of 10 or 35 days Journal of Reproduction and Fertility 72 329-337

Kuneke G, Parvizi N and Elsaesser F (1993) Effect of naloxone and pulsatile luteinizing-hormone-releasing hormone infusions on oestradiol-induced luteinizing hormone surges in immature gilts Journal of Reproduction and Fertility 97 395-401

Parvizi N, Elsaesser F, Smidt D and Ellendorff F (1976) Plasma luteinizing hormone and progesterone in the adult female pig during the oestrous cycle, late pregnancy and lactation, and after ovariectomy and pentobarbitone treatment Journal of Endocrinology 69 193-203

Pomerantz DK, Ellendorff F, Elsaesser F, König A and Smidt D (1974) Plasma LH changes in intact adult, castrated adult and pubertal male pigs following various doses of synthetic luteinizing hormone-releasing hormone $(\mathrm{LH}-\mathrm{RH})$ Endocrinology 94 330-335

Ponzilius K-H, Parvizi N, Elsaesser F and Ellendorff F (1986) Ontogeny of secretory patterns of L.H release and effects of gonadectomy in the chronically catheterized pig fetus and neonate Biology of Reproduction 34 602-612

Sesti LAC and Britt JH (1993) Influence of stage of lactation, exogenous luteinizing hormone-releasing hormone, and suckling on estrus, positive feedback of luteinizing hormone, and ovulation in sows treated with estrogen Journal of Animal Science 71 989-998

SigmaStat ${ }^{(i i)}$ for Windows ${ }^{(i)}$ Statistical Software (1992), Jandel Scientific.

Toran-Allerand CD (1976) Sex steroids and the development of the newborn mouse hypothalamus and preoptic area in vitro: implications for sexual differentiation Brain Research 106 407-412

Van de Wiel DFM, Erkens J, Koops W, Vos E and Van Landeghem AAJ (1981) Periestrous and midluteal time courses of circulating $\mathrm{LH}, \mathrm{FSH}$, prolactin, estradiol-17 $\beta$ and progesterone in the domestic pig Biology of Reproduction $\mathbf{2 4}$ 223-233

Varley MA and Foxcroft GR (1990) Endocrinology of the lactating and weaned sow Journal of Reproduction and Fertility Supplement 40 47-61 